- Outreach teaching is community-based clinical training and non-clinical placements.

- Its benefits include experience of real world patients and health issues, improved skills and confidence, and contact with other health professionals.

- Requirements include suitable staff and premises, a fit with the clinical course, compatibility with health policy, stakeholder support and funding.

- Developments in health policy, the attitude of funding bodies and a review of the dental curriculum offer the opportunity to develop outreach teaching further.

\title{
Outreach teaching: is this the future for dental education?
}

\author{
A. Elkind ${ }^{1}$
}

\begin{abstract}
Increasingly clinical teaching for all health professionals is moving out of teaching hospitals and into community settings. A recent workshop reviewed the place of outreach teaching in undergraduate dental education. This paper defines outreach teaching in terms of its main components; identifies its benefits for different stakeholders; sets out what is required to make it work; and looks at current trends offering opportunities for expansion.
\end{abstract}

In 2001, a workshop ${ }^{1}$ on the role of outreach teaching in the dental curriculum of the future was held in Manchester. Representatives attended from most British dental schools, and from NHS organisations and the GDC. They reviewed the current and future place of outreach teaching in undergraduate education, with a view to developing a submission to the GDC to assist its review of The First Five Years, ${ }^{2}$ which sets out the requirements for undergraduate dental education. The workshop participants concluded that outreach is the way forward as it broadens undergraduate clinical teaching. So what is outreach teaching and why is it of growing interest? This paper looks at its components, benefits and requirements, together with the opportunities for future development.

\section{WHAT IS OUTREACH TEACHING?}

Increasingly clinical teaching for all health professionals is moving out of teaching hospitals and into communitybased settings, under the direction of

${ }^{1}$ Project Manager, University Dental Hospital o Manchester, Higher Cambridge Street, Manchester M156FH

E-mail:andrea.elkind@man.ac.uk

\section{Refereed Paper}

Received 05.11.01; Accepted 03.04.02

๑ British Dental Journal 2002; 193: 111-112 academic departments. This reflects the emphasis on the development and delivery of health services in primary care. ${ }^{3}$ Experience outside the secondary care environment of the dental hospital is particularly relevant to future dentists since most of them will eventually work in the primary care sector. As a result, a number of dental schools have developed courses that take their students into community settings.

The workshop presentations ${ }^{1}$ described a wide range of models of such outreach teaching adopted by individual dental schools. From these, two broad components can be identified. In the first, community dental clinics provide a clinical teaching setting for students. Such programmes have been running, for example, in Manchester and Liverpool for some years and typically focus on areas such as paediatric dentistry, orthodontics, and patients with special needs. The CDS clinics involved are usually located in areas of social deprivation. Teaching is provided by CDS and dental school staff. In Manchester outreach has recently developed further through a pilot to teach restorative dentistry to fourth year undergraduates, which includes links with a PDS initiative. This form of education, which can represent a substantial element of the student's clinical experience, may take place alongside that of other members of the dental team. The aims of this component are to provide experience of treating patients in a primary care setting, to promote teamworking, and to develop an understanding of the wider context in which dentistry is practised.

The focus of the second component is on community-based attachments, where students come into contact with public, patients and other health professionals, and observe the delivery of dental care. In Newcastle-upon-Tyne and Belfast, for example, the undergraduate courses include such features as family attachments, and placements in locations such as residential care homes, primary schools and crèches, as well as CDS clinics and general practices. The aims of this component are to enable students to develop an understanding of the lives and social circumstances of patients, the organisation of health and social care, the delivery of dental services including care for priority groups, health promotion, and public health.

Individual dental schools may combine the two components in varying degrees or emphasise only one. Factors in this choice include the objectives sought, the resources available and the structure of the undergraduate course. The GDC requirements for undergraduate dental education, The First Five Years, ${ }^{2}$ supports this variety of approaches and the workshop concluded 
that no one standard model of outreach teaching is appropriate for all.

The development of outreach teaching is international. For example, in Helsinki the University clinic has been closed, and students now receive their clinical training in the public health system (Meurman, personal conmmunication).

\section{WHAT ARE THE BENEFITS?}

The workshop ${ }^{1}$ identified the benefits for students as:

- Contact with real world patients.

- The development of new skills, including time management, four-handed working, workload management and team working.

- Improved confidence and speed.

- Exposure to a greater variety of patients and procedures.

- Improved communication skills.

- First-hand experience of health issues outside the protected environment of the dental school.

- Contact with other members of the healthcare team.

- A wider view of dentistry.

For the dental school, outreach teaching enhances links with the community; further develops partnership with the NHS; provides a wider pool of teachers and patients; and represents an opportunity for research. For the host organisation, participation offers improved staff motivation and recruitment; a link with an academic centre providing support for clinical governance, research and continuing professional development; plus the opportunity to develop local service provision. Finally for patients, improved local access to treatment is available.

Evaluations $^{4-7}$ of outreach teaching broadly support the conclusions ${ }^{6}$ that it provides a range of beneficial learning experiences for students; that exposing students to a teaching environment other than the dental hospital is of value; and that the experience provides a valuable transition between working as a student and as a qualified professional in practice.

\section{WHAT IS REQUIRED TO MAKE OUTREACH WORK?}

In 1977 Holloway and Dixon ${ }^{4}$ defined the requirements for successful clinical teaching in outreach as suitable premises, suitable staff, and a clinical course organised in a compatible way. In 2002 we can add compatibility with health policy, the support of stakeholders, and funding.

The availability of an infrastructure to support outreach teaching is a key factor, which does not currently exist everywhere. Where it does not, it has to be developed and this implies the need for both capital and revenue funding. Moreover outreach centres, whether pre-existing or new, have to be sited in areas that will provide an appropriate patient base for teaching and are accessible for students.

The staff of the dental school must be willing to adopt change. Not all staff will see outreach as advantageous and their support will have to be gained. Communication, timetabling and training need a careful approach. The logistics of organising a course in this way must be fully thought through and quality standards maintained through monitoring. Outreach teaching has to be linked to and integrated with the rest of the undergraduate programme.

Nor can it be assumed that the local CDS and PCT will adopt the concept without question. The service provided by students must meet the needs of the local population as part of the local dental health strategy. It is important for the NHS to receive fair compensation for providing the facilities through SIFT (Service Increment for Teaching) payments. Local GDPs will need to know that the new service is intended to complement not compete with their own.

\section{OPPORTUNITIES}

Several strands of change offer the opportunity to expand outreach teaching. Modernising NHS Dentistry - Implementing the NHS Plan ${ }^{8}$ identifies improving access as the government's top priority and promotes new approaches and new partnerships as a way of achieving this goal. Moving teaching out of dental hospitals and into the community improves local access to the primary care service, as students will see a greater number of patients. At the same time changes to the CDS and the development of PDS allow more flexible and innovative service provision to be developed, of which outreach teaching can form part. The Department of Health has established Options for Change, a review of the GDS, including education and training. Developing a primary care dental teaching centre may be particularly attractive to a PCT seeking teaching status.

NHS funding bodies, including the former National Purchasing Unit for Dental SIFT (now the National Dental Development Unit) and the former North West Regional Office of the NHS Executive, demonstrated their willingness to support innovation in this field. Changes to the NHS mean that SIFT funds are now the responsibility of the new Workforce Development Confederations. The implications of this change are not yet clear but dental schools have the opportunity to interest the confederations in new approaches to teaching. Developments such as the NHS Local Improvement Finance Trust and the Private Finance Initiative can also be explored. However dental schools cannot expect the NHS to be the sole funder. The academic funding bodies, such as HEFCE and the universities themselves, will also need to be convinced to provide support. The GDC review of The First Five Years ${ }^{2}$ and their view of the way forward will be particularly influential in this respect.

The workshop was funded by the University of Manchester and the University of Liverpool. The author's thanks are due to the participants for their contribution to the thinking in this paper. A full report of the workshop is obtainable from the author.

1. The role of outreach teaching in the dental curriculum of the future. Report of a workshop held at the Manchester Dental Education Centre on 19 February 2001. Eden Bianchi Press: The University of Manchester and the University of Liverpool, Manchester.

2. General Dental Council. The first five years: the undergraduate dental curriculum, 1997.

3. Committee of Vice-Chancellors and Principals. Briefing Note: The University/NHS partnership in the provision of health professional education. Higher Education Briefing Service, Winter, 2000

4. Holloway P, Dixon P. Extra-mural experience for undergraduate dental students. Br DentJ 1977; 143: 146-150.

5. Blinkhorn FA. Evaluation of an undergraduate community-based course in family dentistry. EurJ Dent Educ 2002; 6: 40-44.

6. Barnes J. The Health Centre Programme, The School of Dentistry, the University of Liverpool. Report No 3 : The perceptions of recently qualified dental surgeons and dental therapists. Liverpool Evaluation and Assessment Unit, Department of Education, The University of Liverpool, 1999.

7. Barnes J. The Health Centre Programme, The School of Dentistry, the University of Liverpool. Report No 4 : The perceptions of final year BDS and dental therapy students. Liverpool Evaluation and Assessment Unit, Department of Education, The University of Liverpool, 1999.

8. Department of Health. Modernising NHS Dentistry Implementing the NHS Plan, 2000. Publ: Department of Health. 